\title{
Koroner yavaş akımın ortalama trombosit hacmi/lenfosit oranı ile ilişkisi
}

\section{Relationship between coronary slow flow and mean platelet volume / lymphocyte ratio}

\author{
Murat GÖK*1, Alparslan KURTUL ${ }^{2}$ \\ ${ }^{1}$ Edirne Sultan 1. Murat Devlet Hastanesi, Kardiyoloji Kliniği, Edirne/Türkiye \\ ${ }^{2}$ Ankara Eğitim Araştırma Hastanesi, Kardiyoloji Kliniği, Ankara/Türkiye
}

\section{öz}

Amaç: Bu çalışmanın amacı, kolayca hesaplanabilen yeni bir inflamatuar belirteç olan ortalama trombosit hacmi/ lenfosit oranının koroner yavaş akım şiddeti ile ilişkisini araştırmaktır.

Gereç ve Yöntemler: Kesitsel tipte yapılan bu çalışmada, Nisan 2016 ile Nisan 2017 tarihleri arasında hastanemize başvuran toplam 166 hasta dahil edilmiştir. Koroner yavaş akım grubuna 83 hasta, normal koroner akım grubuna 83 hasta dahil edildi. Tüm hastaların koroner akım hızları Timi Kare Sayımı (TIMI) yöntemi ile hesaplanmıştır. Tüm verilerin analizi için SPSS 22.0 istatistiksel paket programı kullanılmıştır.

Bulgular: Ortalama trombosit hacmi/ lenfosit oranı, koroner yavaş akım grubunda normal koroner akım grubuna göre istatistiksel olarak daha anlamlı bulundu. ( $p<0.001$ ) Çok değişkenli lojistik regresyon analizinde, ortalama trombosit hacmi/ lenfosit oranı koroner yavaş akımın bağımsız öngördürücüsü olduğu bulundu. ( $p<0.001)$ Buna ek olarak, HsCRP, total kolesterol, HDL ile koroner yavaş akım arasında pozitif bir korelasyon saptandı. $(p<0.05)$

Sonuç: Yeni ve basit bir inflamasyon göstergesi olan ortalama trombosit hacmi / lenfosit oranı, koroner yavaş akım saptanan hastalarda daha yüksek bulundu. Bu yüksek oran, koroner yavaş akım saptanan hastaları takipte klinisyenler için önemli bir gösterge niteliği taşıyor olabilir.

Anahtar kelimeler: inflamasyon, lenfosit, ortalama trombosit hacmi, koroner yavaş akım 


\section{ABSTRACT}

Aim: The aim of this study was to investigate the association of the mean platelet volume to lymphocyte ratio, a novel inflammatory marker that is easily calculated, with coronary slow flow severity.

Material and Method: In this cross-sectional study, a total of 166 patients referred to our hospital between April 2016 and April 2017 were included. 83 patients were included in the coronary slow flow group, and 83 patients were included in the normal coronary flow group. Coronary flow velocities of all patients were measured by the Timi Frame Count (TIMI) method. SPSS 22.0 statistical package program was used for analysis of all data.

Results: MPVLR was statistically more significant in coronary slow flow group compared to normal coronary flow group. $(p<0.001)$ In multivariate regression analysis, MVPLR was found to be an independent predictor of coronary slow flow. $(p<0.001)$ In addition, there was a positive correlation between HsCRP, total cholesterol, HDL and coronary slow flow. $(p<0.05)$

Conclusion: Mean platelet volume to lymphocyte ratio, a new and simple indicator of inflammation, was found to be higher in patients with coronary slow flow. This high ratio may be indicative for clinicians following patients with severe coronary slow flow.

Keywords: Inflammation, Lymphocyte, Mean platelet volume, coronary slow flow

\section{Giriş}

Koroner yavaş akım (KYA), anjiografik bir tanı olup koroner arterlerde tıkanıklık olmadan opaklaşmanın yavaşlamasıyla anlaşılmaktadır.(1) Koroner arter hastalığı (KAH) tanısı için anjiyografi yapılan hastalarda KYA insidansının \% 1-7 olduğu bildirilmiştir.(2) Çalışmalar KYA'ın miyokardiyal iskemi, angina ve enfarktüse neden olabileceğini ve çok da masum bir hastalık olmadığını gösteriyor.(3-5) Koroner yavaş akım patofizyolojisi tam olarak bilinmemekle birlikte, olası mekanizmalar: endotel disfonksiyonu, inflamasyon, yaygın ateroskleroz ve artmış trombosit agregasyonu olarak tahmin edilmektedir.(6-10)

Ortalama trombosit hacmi (MPV) trombosit hücrelerinin ortalama boyutunun bir ölçüsüdür. Akut koroner sendrom patogenezinde trombositlerin önemli bir rol oynadığı bilinmektedir.(11) Trombosit boyutuyla trombosit aktivitesi arasında bir ilişki vardır. Daha büyük trombositler enzimatik ve metabolik olarak daha aktiftirler.(12) Lenfosit hücreleri immünolojik yanıt ve inflamasyon ile ilişkilidir. Lenfopeni kardiyovasküler advers olaylarla ilişkili bulunuştur. $(13,14)$

Yapılan son çalışmalar, ortalama trombosit hacminin lenfosit sayısına oranının (MPVLO), inflamasyonun yeni ve dolaylı bir göstergesi olabileceği belirtilmiştir. İnflamasyon ise KYA mın etyopatogenezinde rol oynayan ana patolojidir. Çalışmamızda MPVLO ile KYA mın varlığı ve ciddiyeti arasındaki ilişkiyi araştırdık.

\section{Gereç ve Yöntemler}

Hasta Seçimi
Çalışma hastaları, Nisan 2016 ile Nisan 2017 tarihleri arasında hastanemize başvuran hastalardan seçildi. Kesitsel tipteki bu çalışmada, hastanemize başvuran toplam 166 hasta çalsşmaya dahil edildi; bunlardan 83'ü KYA grubuna, 83'ü NKA grubuna alındı. Dışlanma kriterleri: Akut koroner sendrom tanılı hastalar (ST segment yükselmesi miyokard enfarktüsü (STEMI) ve nonSTEMI), sol ventrikül sistolik disfonksiyonu [sol ventrikül ejeksiyon fraksiyonu (LVEF) <\% 40], böbrek ve karaciğer hastalıkarı olan hastalar, malignite veya başka herhangi bir akut inflamatuvar hastalığı olan hastalar veya kronik inflamatuar bir hastalık nedeniyle non steroid anti-enflamatuar ve kortikosteroid ilaçlarla tedavi olan hastalar ve anemi de dahil olmak üzere hematolojik hastalıkların yanı sıra perkütan koroner müdahale öncesi ve sonrasında koroner arter baypas grefti yapılan hastalar olarak belirlendi.

Hipertansiyon, antihipertansif tedavi kullanımı veya tekrarlanan ölçümlerde 140/90 mmHg'nın üzerindeki kan basıncı tespit etmek olarak tanımlandı. Diyabet ölçütü olarak açlık kan şekeri en az 2 ölçümde > $126 \mathrm{mg} / \mathrm{dl}$ veya şu anda antidiyabetik tedavi kullanımı olarak belirlendi. Hastanemizin Yerel Etik Komitesi çalışma protokolünü onaylamış ve tüm katılımcılar yazılı bilgilendirilmiş onam formunu imzalamıştır.

\section{Laboratuvar parametrelerinin değerlendirilmesi}

Hastaların periferik venöz kan örnekleri hastalar kardiyoloji kliniğine başvurduklarında alındı. Tam kan sayımı parametrelerini ölçmek için otomatik bir kan sayımı (Beckman Coulter analyzer, California, ABD) cihazı kullanıldı. Ölçülen biyokimya parametreleri; kreatinin, total kolestrol, yüksek 
dansiteli lipoprotein kolestrol (HDL-C), düşük yoğunluklu lipoprotein kolestroldü (LDL-C). Yüksek duyarlıklı C-reaktif protein (HsCRP) ölçümü, koroner anjiyografi öncesinde Beckman Coulter analyzer cihazı kullanılarak yapıldı. Tüm hastalara transtorasik ekokardiyografi yapıldı ve sol ventrikül ejeksiyon fraksiyonu için (LVEF) Simpson yöntemi kullanıldı. Ortalama trombosit hacmi/ lenfosit oranı, aynı kan örneğinden elde edilen MPV - lenfosit sayısı(103 / mm3) olarak hesaplandı.

\section{Anjiografik değerlendirme}

Standart anjiyografi radyal veya femoral arterler aracılığıyla standart Judkins tekniği ile 6F kateterleri ve Siemens Axiom Sensis XP cihazı kullanılarak gerçekleştirildi. Tüm anjiyograflar saniyede 30 kare hızında kaydedildi.Tüm katılımcılarda kontrast ajanı olarak Iopamiro (lopamidol-300) kullanıldı. Hastaların akım hızları Gibson ve ark. (15) tarafından gösterildiği gibi TıMı Kare Sayımı tekniği ile belirlendi. Hastaların klinik bilgilerini ve TIMı Kare Sayımını birbirinden ve çalışmadan haberi olmayan iki tecrübeli kardiyolog değerlendirdi. İlk frame olarak arter lümeninin antegrad akımla ilk kolonun tamama yakın veya en az \%70'inin dolduğu an, son frame olarak da arterin distal sonlanım noktasına opağın vardığı an kabul edildi. Sol ön inen koroner arteri (LAD) için apexte distal çatallanma noktası, sirkümfleks ( $\mathrm{Cx}$ ) arteri için geniş olduğu ana gövde veya mojör obtus marjinlerin distal ayırım noktası, sağ koroner arter (RCA) için de Cx'ın ilk majör dalının başlangıcı veya posterolateral uzanımı değerlendirme için kullanıldı. LAD için normal timi frame sayısı (36.2 \pm 2.6$)$ olarak kabul edildi ve LAD frame sayısı hesaplanırken 1.7'ye bölünerek elde edilen değer "düzeltilmiş timi frame sayısı olarak ifade edildi. Ortalama timi frame sayısı hesaplanarak Cx için normal frame sayısı $(22.2 \pm 4.1)$ ve RCA için (20.4 \pm 3.0$)$ olarak kabul edildi.(15)

\section{İstatistiksel değerlendirme}

Tüm verilerin analizi için SPSS 22.0 istatistiksel paket programı (SPSS Inc. Chicago, IL, ABD) kullanıldı. Dağıım analizi için Kolmogorov-Smirnov testi kullanıldı. Normal dağılıma sahip nümerik veriler ortalama \pm standart sapma olarak ve normal dağılım göstermeyen değerler medyan ve çeyreklerarası aralık (IQR) olarak verildi. Kategorik veriler sayı ve yüzde olarak verilmiştir (\%).Parametrik sürekli değişkenleri karşılaştırmak için Student-t testi ve nonparametrik sürekli değişkenleri karşılaştırmak için Mann-Whitney $U$ testi kullanıldı. Çoklu ortalama değerlerin karşılaştırılması, Kruskal-Wallis testleri veya uygun olan varyans analizi ile gerçekleştirildi. Kategorik değişkenleri karşılaştırmak için ki-kare testi kullanıldı. KYA ın potansiyel prediktörlerini bulmak için çok değişkenli lojistik regresyon analizi kullanılmıştır. Çok değişkenli lojistik regresyon analizine $\mathrm{p}<0.15$ olan değişkenler dahil edildi ve çok değişkenli lojistik regresyon analizinde $p<0.05$ istatistiksel olarak anlamlı kabul edildi. Son olarak, KYA'ı öngören prediktif değeri tahmin etmek için ROC eğrisi analizi kullanıldı.

\section{Bulgular}

Çalışmaya toplam 166 hasta (83 KYA ve 83 NKA) dahil edildi. Grupların klinik, laboratuvar ve anjiyografik özellikleri Tablo 1 de sunulmuştur. Kreatinin, total kolestrol, HDL kolesterol, hemoglobin, trombosit sayısı, lenfosit sayısı, MPV, HsCRP, TIMI kare sayısı KYA grubunda istatistiksel olarak anlamlı bulundu. Çok değişkenli lojistik regresyon analizinde KYA ın bağımsız prediktörler araştırıldı. (Tablo 2) Total kolesterol, HDL kolesterol, HsCRP, yüksek MPVLO koroner yavaş akımın öngördürücüleri olarak bulundu.

\begin{tabular}{|c|c|c|c|}
\hline Variables & $\begin{array}{l}\text { Yavaş akım } \\
\qquad(n=83)\end{array}$ & $\begin{array}{l}\text { Normal akım } \\
\qquad(n=83)\end{array}$ & $P$ \\
\hline Yaş, yıl (mean \pm SD) & $58.8 \pm 9,9$ & $58.1 \pm 9.1$ & 0.649 \\
\hline Cinsiyet, erkek, n (\%) & $65(78.3)$ & $59(71.1)$ & 0.284 \\
\hline Diabetes mellitus, n (\%) & $17(20.5)$ & $20(24.1)$ & 0.576 \\
\hline Sigara, n (\%) & $29(34.9)$ & $29(34.9)$ & 1,000 \\
\hline $\begin{array}{l}\text { Sistolik Kan Basıncı, mmHg, } \\
(\text { mean } \pm \text { SD) }\end{array}$ & $135 \pm 14$ & $134 \pm 10$ & 0.488 \\
\hline $\begin{array}{l}\text { Diastolik Kan Basıncl, } \\
\text { mmHg, (mean } \pm S D)\end{array}$ & $76 \pm 12$ & $73 \pm 11$ & 0.151 \\
\hline Kreatinin, $\mathrm{mg} / \mathrm{dl}($ mean $\pm \mathrm{SD})$ & $1.1 \pm 0.5$ & $0.8 \pm 0.2$ & 0.006 \\
\hline Total Kolesterol, ( mean \pm SD ) & $179 \pm 51$ & $152 \pm 25$ & $<0.001$ \\
\hline LDL-C, mg/dl ( mean \pm SD ) & $109 \pm 40$ & $102 \pm 23$ & 0.232 \\
\hline $\mathrm{HDL}-\mathrm{C}, \mathrm{mg} / \mathrm{dl}(\mathrm{mean} \pm \mathrm{SD}$ ) & $40 \pm 10$ & $44 \pm 10$ & 0.011 \\
\hline $\begin{array}{l}\text { Trigliserid, mg/dl ( medi- } \\
\text { an-IQR ) }\end{array}$ & $127(92-215)$ & $130(105-142)$ & 0.368 \\
\hline Hemoglobin, g/dl (mean \pm SD) & $13.6 \pm 1.9$ & $14.6 \pm 1.2$ & $<0.001$ \\
\hline $\begin{array}{l}\text { Trombosit, x103/mm3 } \\
\text { (mean } \pm \text { SD) }\end{array}$ & $238 \pm 60$ & $279 \pm 79$ & $<0.001$ \\
\hline WBC ( mean \pm SD ) & $8.1 \pm 2.1$ & $7.8 \pm 1.2$ & 0.282 \\
\hline Monosit ( mean \pm SD ) & $568 \pm 165$ & $547 \pm 149$ & 0.387 \\
\hline Lenfosit ( mean \pm SD) & $2.0 \pm 0.7$ & $4.4 \pm 1.3$ & $<0.001$ \\
\hline MPV $($ mean $\pm S D)$ & $8.6 \pm 1.1$ & $8.0 \pm 0.7$ & $<0.001$ \\
\hline RDW ( mean $\pm S D)$ & $15.1 \pm 2.4$ & $15.1 \pm 3.4$ & 0.864 \\
\hline Kalp Hızı ( mean \pm SD ) & $75 \pm 9$ & $73 \pm 7$ & 0.084 \\
\hline $\begin{array}{l}\text { High sensitive CRP, } \\
\text { (median-IQR) }\end{array}$ & $6.5(4.2-11.0)$ & $4.0(1.2-5.3)$ & $<0.001$ \\
\hline TFC value ( mean \pm SD ) & $48 \pm 17$ & $16 \pm 5$ & $<0.001$ \\
\hline $\begin{array}{l}\text { MPV/Lenfosit Oranı } \\
\text { (median-IQR) }\end{array}$ & $4.39(3.23-6.4)$ & $1.83(1.41-2.31)$ & $<0.001$ \\
\hline
\end{tabular}




\begin{tabular}{|c|c|c|c|c|}
\hline $\begin{array}{l}\text { Table 2: Multivariate logistic regression analizinde kor } \\
\text { yavaş akımın prediktörleri. } \\
\qquad \text { Multivariated Model }\end{array}$ & \multirow{3}{*}{ 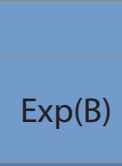 } & \multicolumn{3}{|c|}{ Multivariated Model } \\
\hline & & \multicolumn{2}{|c|}{$95 \% \mathrm{Cl}$} & \multirow{2}{*}{$P$} \\
\hline & & Lower & Upper & \\
\hline Hemoglobin & 0.926 & 0.647 & 1.324 & 0.673 \\
\hline Trombosit & 1.003 & 0.993 & 1.013 & 0.532 \\
\hline Kreatinin & 13.043 & 0.725 & 234.565 & 0.081 \\
\hline Total Kolesterol & 1.038 & 1.016 & 1.059 & 0.001 \\
\hline $\mathrm{HDL}$ & 0.924 & 0.861 & 0.992 & 0.029 \\
\hline MPV & 1.020 & 0.461 & 2.260 & 0.960 \\
\hline $\mathrm{HsCRP}$ & 1.390 & 1.127 & 1.713 & 0.002 \\
\hline Kalp hızı & 1.006 & 0.939 & 1.079 & 0.856 \\
\hline MPV/LO & 3.550 & 1.862 & 6.768 & 0.001 \\
\hline
\end{tabular}

Ortalama trombosit hacmi/ lenfosit oranının KYA için ayırt edici kabiliyetinin araştırılması için yapılan ROC eğrisinde, eğri altındaki alanın 0.946 olduğu belirlendi, MPV için ise bu alan 0.647 olarak hesaplandı. Youden indeksiyle $(\mathrm{J}=\mathrm{max}$ \{Sensitivity + Specificity - 1\}) MPVLO> 2.68 için optimal bir kestirim değeri bulduk. Bu da KYA varlığını \% 89.2 duyarlılıkla ve \% 90.4 özgüllükle ile öngörmüştür (Şekil 1)

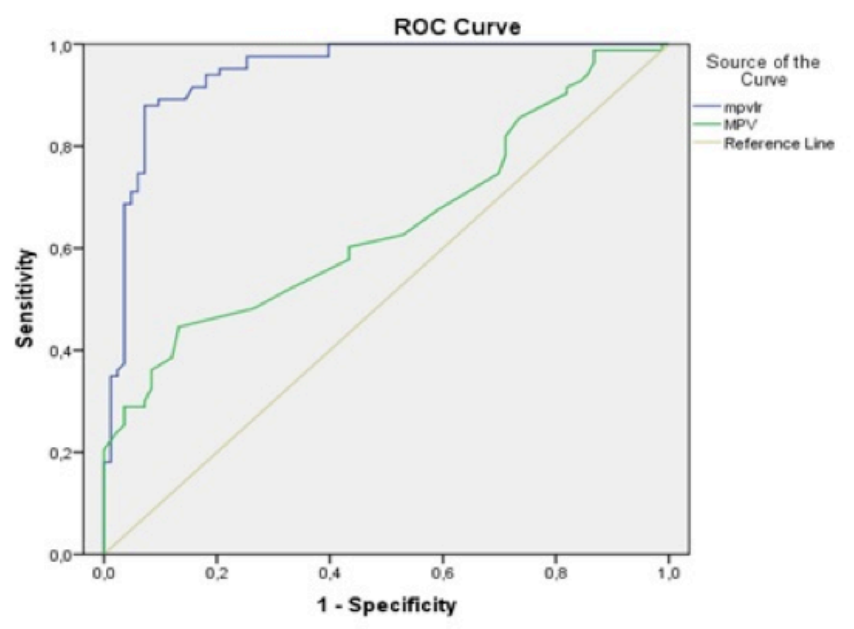

Şekil 1: ROC analizi ile MVPLO nın KYA öngördürme gücü.

\section{Tartışma}

Bu çalışmada MPVLO ve KYA arasında anlamlı bir ilişki bulundu. Bildiğimiz kadarıyla bu, KYA hastalarında inflamatuvar bir yeni belirteç olan MPVLO'nı araştıran ilk çalışmadır ve sonuçları NKA hastalarıyla karşılaştırmıştır.

Trombositler aterotrombotik olaylar, pıhtılaşma ve inflamasyon süreçlerinde önemli rol oynayan kan hücreleridir.(16) Trombosit parametreleri arasında ortalama trombosit hacmi, trombosit sayısı, plateletocrit ve trombosit dağılımı bulunur. Ortalama trombosit hacmi en çok çalışılan trombosit aktivasyon belirteçlerinden biridir ve büyük trombositler önemlidir, çünkü hem trombojeniktirler hem de daha reaktiftirler. $(17,18)$ Yapılan bir çalışmada MPV'nin iskemik inmeli hastalarda daha yüksek olduğu gösterilmiştir.(19) STEMI hastalarında yapılan yeni bir araştırmada yüksek MPV düzeyleri, klinik prezentasyonun şiddeti, revaskülarizasyonun daha kötü sonuçları, hastane ve 12 aylık mortalitede artış ile ilişkili olduğu gösterilmiştir. (20) STEMI hastalarında yapılan başka bir çalışmada, perkütan koroner girişim (PKG) yapılan hastalarda yüksek MPV düzeyi 6 aylık mortalite ile ilişkiliydi.(21) Sarli ve arkadaşlarının yaptığı bir çalışmada STEMI hastalarında, yüksek MPV seviyelerinin girişim sonrası kötü miyokardiyal blush ile ilişkili olduğunu gösterilmiştir.(22) Buna ek olarak, Yang ve arkadaşları kararlı ve kararsız angina pektorisli hastalarda MPV'nin perkütan translüminal koroner anjiyoplastiden (PTCA) sonra bir restenoz belirteci olduğunu gösterdiler.(23)

Öte yandan akut kardiyovasküler olaylarda lökosit sayılarının azaldığı rapor edilmiş ve lenfosit sayısı ile kardiyovasküler mortalite arasında ters bir ilişki olduğu bildirilmiştir.(24) Düşük lenfosit sayısı (DLS), sistemik inflamatuar yanıt sırasında sık görülen bir bulgudur ve DLS'nın hızlanmış aterosklerozda klinik ve hayvan çalışmalarında rol oynadığını gösterilmiştir. Buna ek olarak, DLS, MI tanısı için iyi bir tanı yeteneği, daha düşük ejeksiyon fraksiyonu, daha büyük bir miyokardiyal nekroz ile ve mikrovasküler obstrüksiyonun derecesi ile korelasyonu gösterilmiştir.(25-27) Ayrıca, son gözlemsel çalışmalarda, lenfopeni kronik veya akut kalp yetmezliği olan hastalarda prognostik belirteç olarak ortaya çıkmıştır. $(28,29)$

Buna ek olarak, KYA'da total kolesterol düzeyinin belirgin olarak yüksek, HDL kolesterol düzeyinin ise daha düşük olduğunu bulduk. KYA ın öngörücüleri iki çalışmada araştırılmış ve iki grup arasında da total kolesterol düzeyi anlamlı değildir, HDL kolesterol düzeyi ise KYA hastalarında daha düşük bulunmuştur. $(30,31)$ Koroner yavaş akım, KAH'nın bir varyantı olduğu bilinmektedir ve KYA hastalarında total kolesterol düzeyinin yüksek olması, HDL kolesterol düzeyinin düşük olması literatür bilgisiyle uyuşmaktadır.

Koroner yavaş akım, girişimsel kardiyologlar tarafından, ana epikardiyal koroner arterlerde aterosklerotik bir stenoz olmaksızın, opaklaşmasında bir gecikmenin yaşadığı klinik bir durum olarak tanımlanmıştır.(1) Bununla birlikte, KYA fenomeninin patofizyolojik mekanizmaları belirsizliğini korumaktadır; küçük damar- larda fonksiyon bozukluğu, 
vazokonstriktör ve vazodilatatör faktörler arasındaki dengesizlik ve trombosit fonksiyon bozukluğu gibi bazı hipotezler bulunmaktadır. KYA genellikle aterosklerotik kalp hastalığının bir varyantı olarak düşünülür ve aterosklerozun temel mekanizması da inflamatuvar süreçtir.(7) HsCRP, genel bir inflamatuar belirteçtir ve KYA Iı hastalarda yüksek bulunur. (32) Ayrıca KYA mekanizmasını açıklayacak birçok basit ve kullanışlı kan parametresi belirlenmiştir. Bunlardan biri lenfosit monosit oranıydı ve inflamasyon belirteçleri ve KYA ile ilişkili bulundu. $(33,34)$

Bu çalışmada rutin hemogramda görülen iki kan parametresinin oranı olan MPVLO nın KYA ile olan ilişkisini araştırdık. Bu parametre daha önce sadece bir kez çalışılmıştı ve akut MI geçiren hastalarda yüksek MPVLO, kötü ve kısa vadeli mortaliteyle ilişkili bulundu.(35)

Çalışmamızın bazı kısıtlılıkları vardır. Birincisi, örneklem büyüklüğümüz nispeten küçüktür. İkinci olarak, çalışma popülasyonumuz obstrüktif koroner arter hastalığı grubunu kapsamamaktadır. Son olarak, intravasküler ultrason gibi gelişmiş testleri kullanamadığımız için, kontrol grubumuzun koronerlerinin tamamen normal olduğunu teyit edemedik.

\section{Sonuç}

Bulgularımız, daha düşük MPVLO düzeyinin KYA ile anlamlı ve bağımsız olarak ilişkili olduğunu ortaya koymuştur. Ortalama trombosit hacmi/ lenfosit oranı, hemogramdan basitçe hesaplanabilir ve bu parametre, inflamatuvar ve aterosklerotik yük açısından daha yüksek risk altında olan hastaları tanımlamak için bir gösterge olarak kullanılabilir.

\section{Çıkar çatışması / finansal destek beyanı}

Bu yazıdaki hiçbir yazarın herhangi bir çıkar çatışması yoktur. Yazının herhangi bir finansal desteği yoktur

\section{Kaynaklar}

1. Tambe AA, Demany MA, Zimmerman HA, Mascarenhas E. Angina pectoris and slow flow velocity of dye in coronary arteries. A new angiographic finding. Am Heart J 1972; 84: 66-67

2. Goel PK, Gupta SK, Agarwal A, Kapoor A. Slow coronary flow: a distinct angiographic subgroup in syndrome X. Angiology 2001; 52: $507-14$

3. Tatli E, Yildirim T, Aktoz M. Does coronary slow flow phenomenon lead to myocardial ischemia? Int J Cardiol 2009; 131: 101-2

4. Cesar L, Ramires J, Serrano JC at al. Slow coronary run-off in patients with angina pectoris: clinical significance and thallium-201 scintigraphic study. Braz J Med Biol Res 1996; 29: 605-13
5. Nurkalem Z, Alper AT, Orhan AL at al. Mean platelet volume in patients with slow coronary flow and its relationship with clinical presentation. Turk Kardiyol Dern Ars 2008; 36: 363-67

6. Mosseri M, Yarom R, Gotsman MS, Hasin Y. Histologic evidence for small-vessel coronary artery disease in patients with angina pectoris and patent large coronary arteries. Circulation 1986; 74: 964-72

7. Li JJ, Qin XW, Li ZC at al. Increased plasma C-reactive protein and interleukin- 6 concentrations in patients with slow coronary flow. Clin Chim Acta 2007; 385: 43-47

8. Turhan H, Saydam GS, Erbay AR at al. Increased plasma soluble adhesion molecules; ICAM-1, VCAM-1, and E-selectin levels in patients with slow coronary flow. Int J Cardiol 2006; 108: 224-30

9. Cakmak M, Tanriverdi H, Cakmak N, Evrengul H, Cetemen S, Kuru O. Simvastatin may improve myocardial perfusion abnormality in slow coronary flow. Cardiology 2008; 110: 39-44

10. Gökçe $M$, Kaplan S, Tekelioğlu Y, Erdoğan T, Küçükosmanoğlu M. Platelet function disorder in patients with coronary slow flow. Clin Cardiol 2005; 28: 145-48

11. Massberg S, Schulz C, Gawaz M. Role of platelets in the pathophysiology of acute coronary syndrome. Semin Vasc Med 2003; 3: 147-62

12. Thompson, $C B$, Eaton, $K A$, Princiotta, Rushin CA, Valeri CR. Size dependent platelet subpopulations: relationship of platelet volume to ultrastructure, enzymatic activity, and function. $\mathrm{Br} J$ Haematol 1982; 50: 509-19

13. Horne BD, Anderson JL, John JM et al. Which white blood cell subtypes predict increased cardiovascular risk? J. Am Coll Cardiol 2005; 45: 1638-43

14. Núñez J, Miñana G, Bodí $V$ at al. Low lymphocyte count and cardiovascular diseases. Curr Med Chem 2011; 18: 3226-33

15. Gibson CM, Cannon CP, Daley WL et al. TIMI frame count a quantitative method of assessing coronary artery flow. Circulation 1996; 93: 879-88

16. Davì G, Patrono C. Platelet activation and atherothrombosis. N Engl J Med 2007; 357: 2482-94

17. Arevalo-Lorido JC, Carretero-Gomez J, Alvarez-Oliva A et al. Mean platelet volume in acute phase of ischemic stroke, as predictor of mortality and functional outcome after 1 year. J Stroke Cerebrovasc Dis 2013; 22: 297-303

18. Vagdatli E, Gounari E, Lazaridou E, Katsibourlia E, Tsikopoulou F, Labrianou I. Platelet distribution width: a simple, practical and specific marker of activation of coagulation. Hippokratia 2010; 14: 28-32 
19. O'Malley $T$, Langhorne P, Elton RA, Stewart C. Platelet size in stroke patients. Stroke 1995; 26: 995-99

20. Papanas N, Mikhailidis DP. Mean platelet volume: a predictor of mortality in diabetic and non-diabetic patients with STEMI? J Diabetes Complications 2014; 28: 581-82

21. Akgul O, Uyarel $\mathrm{H}$, Pusuroglu $\mathrm{H}$ et al. Prognostic value of elevated mean platelet volume in patients undergoing primary angioplasty for ST-elevation myocardial infarction. Acta Cardiol 2013; 68: 307-14

22. Sarli B, Baktir AO, Saglam H et al. Mean platelet volume is associated with poor postinterventional myocardial blush grade in patients with ST-segment elevation myocardial infarction. Coron Artery Dis 2013; 24: 285-89

23. Yang A, Pizzulli L, Lüderitz B. Mean platelet volume as marker of restenosis after percutaneous transluminal coronary angioplasty in patients with stable and unstable angina pectoris. Thromb Res 2006; 117: 371-77

24. Dragu R, Khoury S, Zuckerman R et al. Predictive value of white blood cell subtypes for long-term outcome following myocardial infarction. Atherosclerosis 2008; 196: 405-12

25. Thomson S.P, Gibbons R.J, Smars P.A et al. Incremental value of the leukocyte differential and the rapid creatine kinase-MB isoenzyme for the early diagnosis of myocardial infarction. Ann Intern Med 1995; 122: 335-41

26. Blum A, Sclarovsky S, Rehavia E, Shohat B. Levels of T-lymphocyte subpopulations, interleukin-1 beta, and soluble interleukin-2 receptor in acute myocardial infarction. Am Heart J 1994; 127: 1226-30

27. Ommen S.R, Gibbons R.J, Hodge D.O, Thomson S.P. Usefulness of the lymphocyte concentration as a prognostic marker in coronary artery disease. Am J Cardiol 1997; 79: 812-14
28. Huehnergarth K.V, Mozaffarian D, Sullivan M.D et al. Usefulness of relative lymphocyte count as an independent predictor of death/ urgent transplant in heart failure. Am J Cardiol 2005; 95: 1492-95

29. Acanfora D, Gheorghiade M, Trojano L et al. Relative lymphocyte count: A prognostic indicator of mortality in elderly patients with congestive heart failure. Am Heart J 2001; 142: 167-73

30. Sezgin AT, Barutcu I, Sezgin N at al. Contribution of plasma lipid disturbances to vascular endothelial function in patients with slow coronary flow. Angiology 2007; 57: 694-701

31. Yazici M, Demircan S, Aksakal E at al. Plasma insulin, glucose and lipid levels, and their relations with corrected TIMI frame count in patients with slow coronary flow. Anadolu Kardiyol Derg 2003; 3: 222-26

32. Barutcu I, Sezgin AT, Sezgin $\mathrm{N}$ et al. Increased high sensitive CRP level and its significance in pathogenesis of slow coronary flow. Angiology 2007; 58: 401-7

33. Yayla Ç, Akboğa MK, Gayretli Yayla K et al. A novel marker of inflammation in patients with slow coronary flow: lymphocyteto-monocyte ratio. Biomark Med 2016; 10: 485-93

34. Akboga MK, Canpolat U, Balci KG et al. Increased Platelet to Lymphocyte Ratio is Related to Slow Coronary Flow. Angiology $2016 ; 67: 21-6$

35. Hudzik B, Szkodziński J, Lekston A, Gierlotka M, Poloński L, Gąsior M. Mean platelet volume-to-lymphocyte ratio:novel marker of poor short-and long term prognosis in patients with diabetes mellitus and acute myocardial infarction J Diabetes Complications 2016; 30: 1097-102 